\title{
A educação especial em projetos de assentamentos da reforma agrária no municipio de Conceição do Araguaia - PA
}

Special education in settlement projects of agrarian reform in the municipality of conceição do Araguaia - PA

Ramofly Bicalho ${ }^{1}$

Leandro Ferreira Silva ${ }^{2}$

Allan Rocha Damasceno ${ }^{3}$

\section{Resumo}

Alicerçada nos marcos históricos e políticos na luta pela terra, pela vida e pela Educação do Campo na Amazônia Paraense, esta pesquisa buscou caracterizar a organização das escolas do campo no que se refere às condições de inclusão de estudantes público-alvo da Educação Especial que vivem e estudam em projetos de assentamentos da reforma agrária localizados no municipio de Conceição do Araguaia, PA. O município lócus deste estudo possui 37 (trinta e sete) projetos de assentamentos da reforma agrária, com 4.270 (quatro mil, duzentas e setenta) famílias assentadas. No ano 2016, foram cadastrados 71 (setenta e um) estudantes público-alvo da Educação Especial no Censo Escolar no municipio de Conceição do Araguaia. Sobre a fundamentação teórico-metodológico, a mesma se estrutura com base na Teoria Crítica da Sociedade. Nesse sentido, recorre-se ao pensamento de Theodor Adorno, que se constitui no próprio método da pesquisa, ou seja, os dados levantados dos indicadores oficias foram analisados e discutidos considerando o pensamento do filósofo citado. Nossos resultados apontaram que a Educação Especial em assentamentos

1 Docente na UFRRJ - Universidade Federal Rural do Rio de Janeiro, Campus Seropédica. Lotado no Departamento de Educação do Campo, Movimentos Sociais e Diversidade. Docente na Licenciatura em Educação do Campo, no PPGEA - Programa de Pós-Graduação em Educação Agrícola e no PPGEduc - Programa de Pós-Graduação em Educação, Contextos Contemporâneos e Demandas Populares. Pós-Doutorado em Educação na Universidade Federal Fluminense - UFF. Atuo com as seguintes temáticas: História da Educação do Campo e os Movimentos Sociais. Educação Popular e Educação de Jovens e Adultos. E-mail: ramofly@gmail.com.

2 Técnico em Assuntos Educacionais no IFPA - Conceição do Araguaia/PA.Mestre em Educação - UFRRJDoutorando em Educação - UFSCar. E-mail: leandrosuperbio@gmail.com.

${ }^{3}$ Docente na UFRRJ - Universidade Federal Rural do Rio de Janeiro, Campus Seropédica. Lotado no Departamento de Educação do Campo, Movimentos Sociais e Diversidade. Docente na Licenciatura em Educação do Campo, no PPGEA - Programa de Pós-Graduação em Educação Agrícola e no PPGEduc - Programa de Pós-Graduação em Educação, Contextos Contemporâneos e Demandas Populares. Pesquisador do LEPEDI. Email: lepedi-ufrrj@hotmail.com. 
do município de Conceição do Araguaia, PA se realiza em condições precárias e, por conseguinte, há uma invisibilidade desse público, considerando que nenhuma das escolas do campo até o ano de 2016 oferecia o Atendimento Educacional Especializado para o público-alvo da Educação Especial.

Palavras-chaves: Educação Especial. Educação do Campo. Educação Inclusiva; Amazônia Paraense.

\section{Abstract}

Based on the historical and political milestones in the struggle for land, life and field education in the Amazon region of Paraense, this research aimed to characterize the organization of rural schools in terms of the conditions of inclusion of target Special Education students living and study in agrarian reform settlements projects located in the municipality of Conceição do Araguaia, PA. The municipality of this study has 37 (thirty seven) agrarian reform settlements, with 4,270 (four thousand, two hundred and seventy) settled families (INCRA, 2016). In the year 2016, 71 (seventy-one) students were enrolled in Special Education in the School Census in the municipality of Conceição do Araguaia. On the theoretical-methodological basis, it is structured based on the Critical Theory of Society. In this sense we refer to Theodor Adorno's thought, which is the very method of research, that is, the data collected from official indicators were analyzed and discussed considering the philosopher's thinking. Our results pointed out that the Special Education in settlements of the municipality of Conceição do Araguaia, PA is carried out in precarious conditions and, therefore, there is an invisibility of this public, considering that none of the schools of the field until the year 2016 offered the Specialized Educational Assistance to the target audience of Special Education.

Key-words: Special education. Rural Education. Inclusive education. Amazon Paraense.

\section{Introdução}

Presenciamos nos últimos anos politicas públicas educacionais inclusivas que culminaram com o aumento do número de matrículas de estudantes público-alvo da Educação Especial, em todas as etapas da educação, da Educação Infantil ao Ensino Superior. A inclusão das pessoas com deficiência é hoje um tema debatido em todo mundo, e no Brasil essa discussão tem se ampliado consideravelmente. 
Esse avanço nas políticas de inclusão social no Brasil promoveu mudanças estruturais na legislação brasileira, atingindo um público que até então era invisibilizado. Essa nova abordagem, denominada Educação Inclusiva, promoveu a intensificação de ações voltadas para a inclusão de segmentos sociais, que, por diversas razões, estiveram à margem dos processos educacionais, reconhecendo que a educação é um direito de todas as pessoas.

O Brasil, ao se tornar signatário de acordos internacionais, como a Declaração de Salamanca (1994), aprovada na conferência esta abordou os "princípios, politicas e práticas na área das necessidades educativas especiais", assumiu o compromisso de que a educação escolar deveria ser garantida a todas as pessoas sem qualquer tipo de discriminação, seja de classe social, de etnia, ou muito menos de localização geográfica. Nesse contexto, estão às pessoas que vivem no campo e as pessoas com deficiência. Infelizmente, o que temos presenciado é o desmontes das políticas públicas de nucleação e fechamento de escolas do campo. Só no ano de 2014, foram fechadas mais de quatro mil escolas do campo no Brasil. Nos últimos 15 anos, 37 mil unidades tiveram suas atividades encerradas, o que dá em média oito escolas rurais fechadas por dia. (Censo escolar/INEP, 2014)

Se vivemos um momento de desconstrução e fechamentos das escolas do campo, o que dizer então dos alunos público-alvo da Educação Especial que vivem em áreas rurais? Ambas as modalidades da Educação Inclusiva ocuparam/ocupam um lugar periférico e marginal no cenário educacional brasileiro, pois, historicamente, a Educação Especial constitui-se como um "apêndice indesejável” na educação comum (MAZZOTA,2005), e a Educação do Campo é considerada como um "resíduo" do sistema educacional urbano (FERNANDES; CERIOLI; CALDART, 2011). Essa relação permite dialogar e discutir as causas dessa invisibilidade perante as ações do poder público, como caracteriza Nozu (2017, p.16):

[...] investigar a interface entre a Educação Especial e a Educação do Campo é dispor-se a transitar num território intersticial, situado entre porteiras marginais - do descaso do poder público, do silenciamento 
acadêmico e da estigmatização social - e fronteiras culturais - de saberes, de práticas pedagógicas, de modos de constituição dos sujeitos, que podem ser tanto consensuais quanto conflituosos.

Há um certo ocultamento e invisibilidade deste público. Assim, se as pesquisas em Educação Especial apontam os desafios das escolas localizadas em áreas urbanas, estes se intensificam muito mais nas populações do campo. A invisibilidade das deficiências está presente tanto na cidade, quanto no campo, mas neste último se torna mais gritante, por todo o cenário de exclusão que o homem do campo vive. Os estudantes público-alvo da Educação Especial vivem essa dupla privação, são excluídos porque são trabalhadores do campo, tendo todo um histórico de conflitos e marginalização, por não ter uma reforma agrária justa, ausência de políticas públicas de incentivo para fixação do homem no campo, com condições reais dignas de vida. As pessoas com deficiência que vivem nessas famílias têm sobreposta essa marginalização da condição da deficiência, que fica mais acentuada não só pelo preconceito, mas pela ausência de saúde, de habitação, de transporte adequado e de escolarização, como bem pontua Caiado (2017, p. 6):

\begin{abstract}
As barreiras para a pessoa com deficiência ter participação social são muitas, seja no campo ou na cidade. Barreiras arquitetônicas, de comunicação e de atitudes são frequentes com a ausência de acessibilidade para a locomoção, de interação e de convivência social. Prédios com escadas, corredores sem sinalização, banheiros sem adaptação; ausência de tecnologias e de formação para os profissionais da educação são exemplos cotidianos vivenciados no contexto escolar. Se um dos maiores problemas das escolas no campo são os deslocamentos dos alunos e professores, seja por transporte rodoviário ou pluvial, isso se agrava muito quando o aluno tem alguma deficiência e necessita de transporte escolar adaptado.
\end{abstract}

O contexto da Educação Especial no Campo ganha ainda maior relevância na Amazônia, pelo seu cenário regional, geográfico e político, e especialmente no estado do Pará. A Amazônia Paraense está localizada no extremo norte do país, o segundo maior estado em termo de extensão territorial do Brasil. Esse estado caracteriza-se como o mais rico e populoso 
da Região Norte, com uma população estimada em 8.175.113 habitantes, dos quais 68\% residem na zona urbana e 31,5\% na área rural (Censo, 2010). Comparando com a média nacional, o estado possui um índice populacional de pessoas residindo no campo elevado, o que caracteriza como um estado com perfil agrário, onde residem diversas populações tradicionais como: indígenas, quilombolas e camponesas.

Os dados estatísticos educacionais do censo escolar de 2016 apontam que 30,65\% dos estudantes paraenses estudam nas escolas localizadas em áreas rurais, superando a média nacional de 16,28\%. No que se refere ao público-alvo da Educação Especial, 25,8\% dos estudantes estão matriculados nas escolas do campo na Amazônia Paraense (Censo Escolar/INEP, 2016).

Os assentamentos do estado do Pará correspondem a 52,5\% dos assentamentos da Região Norte: são 1067 projetos de assentamentos da reforma agrária em todo o estado, com um total de 224.798 famílias assentadas. Dos 143 municípios que compõem o Pará, 79 possuem assentamentos em seus territórios. Os números de assentamentos do sul paraense correspondem a 15,65\% dos assentamentos estado. (INCRA, 2016).

A região do sul do Pará é composta de 15 municipios: Água Azul do Norte, Bannach, Conceição do Araguaia, Cumaru do Norte, Floresta do Araguaia, Ourilândia do Norte, Pau D’arco, Redenção, Rio Maria, Santa Maria das Barreiras, Santana do Araguaia, São Félix do Xingu, Sapucaia, Tucumã e Xinguara (IDESP, 2013). A região abriga uma população de 510.722 habitantes, dos quais 194.074 vivem na área rural, o que corresponde a 38\% do total (IBGE, 2014). Essa região ocupa uma área de $174.051,89 \mathrm{~km}^{2}$, o que corresponde a 13,59\% do território paraense. Nela, há 19.824 agricultores familiares, 28.246 famílias assentadas e 10 terras indígenas (Painel de assentamentos, 2016, INCRA). Seu IDH médio é de $0,710^{4}$.

\footnotetext{
${ }^{4} \mathrm{O}$ Índice de Desenvolvimento Humano (IDH) é uma medida comparativa usada para classificar os países pelo seu grau de "desenvolvimento humano" e para ajudar a classificar os países como desenvolvidos: 0,944 -0,802 (desenvolvimento humano muito alto), em
} 
Segundo o painel de assentamentos do INCRA, existem atualmente 167 projetos de assentamentos da reforma agrária no Sul do Pará, onde residem 28.246 famílias assentadas (INCRA, 2016). A localidade abrange uma superfície de quase 2 milhões de hectares, e é constituída principalmente de pequenos produtores, posseiros, integrantes do Movimentos dos Trabalhadores Rurais Sem Terra (MST), que vieram na busca de bens sociais e pela exclusão social de outras regiões do país. Esta região abriga uma das maiores aéreas de projeto de assentamento de reforma agrária no Brasil.

Os assentamentos no sul do Pará surgiram em virtude de vários conflitos agrários, especialmente entre as décadas de 1960 e 1990. Isso se deve porque grandes empresas e/ou proprietários do Centro Sul do Brasil foram incentivados a adquirirem títulos e terras dos governos estaduais da região norte do País. O grande problema é que em muitos destas terras existiam posseiros que já residiam há muito tempo nessas propriedades, mas não tinham documentos que os legitimassem como verdadeiros donos.

Alguns pesquisadores como Ianni (1978), Martins $(1984,1991,1999)$ e Hébete (2004) explicam que os conflitos e a violência no campo se sucederam nesse período em virtude dos posseiros que residiam nas terras devolutas, pois, ao serem perseguidos e expulsos, resolveram reagir a esses grandes empreendimentos instalados na Região Norte.

A luta pela terra da parte do Sul do Pará intensificou-se ano a ano. Desde 1966, vários registros de violência agrária são registrados nos jornais de circulação da época, com fatos históricos que tiveram repercussão nacional, como a Guerrilha do Araguaia. O agravamento da crise fundiária ocorreu no final da década de 1970, devido à chegada de milhares de camponeses vindos de diversas regiões do país, principalmente dos estados do Maranhão e Norte Goiano (hoje Tocantins), já que, por não encontrarem terras livres, teriam iniciado diversas ocupações em grandes propriedades e conflitos de maiores proporções teriam iniciado.

desenvolvimento: 0,801-0,555 (desenvolvimento humano médio e alto) e subdesenvolvidos: 0,554 (desenvolvimento humano baixo). 
Segundo dados da Comissão Pastoral da Terra (CPT), somente no estado do Pará, durante o período de 1971 a 2004, ocorreram 772 mortes relacionadas aos conflitos de terra, grande parte destes assassinatos na região sul do Pará. Diversas ocupações de terras surgiram nesse período, dando início a vários acampamentos, e através das lutas dos movimentos sociais muitas dessas propriedades foram desapropriadas gerando grandes projetos de assentamentos de reforma agrária no sul do Pará.

Nesse contexto de luta pela terra, pela vida e pela educação em assentamentos do sul do Pará, estão os estudantes público-alvo da Educação Especial. Os indicadores educacionais nos apresentam que cerca de $1 / 4$ e/ou 25\% dos estudantes dessa modalidade estudam nas escolas do campo no sul paraense, superando a média nacional de $13 \%$.

O município de Conceição do Araguaia é a cidade lócus da pesquisa, localizada no sul paraense, distante há $1.200 \mathrm{~km}$ da capital do estado, Belém, situada à margem esquerda do Rio Araguaia, fazendo divisa com estado do Tocantins. Segundo dados do censo populacional (IBGE, 2010), Conceição do Araguaia, tem aproximadamente 45.557 habitantes, onde 32.464 residem na zona urbana, enquanto que 13.093 residem no campo, o que representa aproximadamente $1 / 3$ dos seus habitantes.

Parte do contingente populacional da cidade reside no campo, fazendo com que o município possua uma das maiores aéreas de assentamento da reforma agrária no Brasil. São 37 projetos de assentamento, onde segundo dados do Instituto de Colonização de Reforma Agrária (INCRA, 2015) existem 4.270 famílias assentadas no município. São vários agricultores familiares que tem sérias dificuldades de acesso aos serviços básicos de saúde, estradas, habitação e principalmente de educação. O modelo de desenvolvimento imposto na região não difere das zonas rurais da Amazônia. A infraestrutura construída nas áreas de assentamento não atende às necessidades dos agricultores e suas famílias. E no que se refere à educação, não é diferente. A organização de Educação do Campo está estruturada em grande parte sob a forma de sistema modular de ensino. 
A Secretaria Municipal de Educação (SEMED) de Conceição do Araguaia, contava no ano de 2015 com 5.679 estudantes matriculados, dos quais 2.146 estavam inseridos em escolas do campo/da zona rural, ou seja $37,78 \%$ dos estudantes da rede municipal de ensino se encontravam no campo. No ano de 2016, foram cadastrados no censo escolar 4.984 estudantes: destes, 2.200 estavam matriculados em escolas campesinas, cerca de 44,14\% era público da Educação do Campo. (Microdados de matrícula do censo escolar/INEP 2015 e 2016). Um aumento de 6,36\% de matrículas em escolas do campo quando comparado ao ano de 2015.

Os dados do censo populacional, apontam que $85,8 \%$ do percentual da população de 4 a 17 anos com deficiência no Brasil frequentam a escola. No estado do Pará, 83,5\% desses estudantes matriculados na Educação Básica estavam estudando em salas comuns. Conceição do Araguaia, possui 761 crianças e adolescentes com alguma deficiência em idade escolar. Desse total, $77,9 \%$ frequentam a escola, o que equivale a 351 alunos inclusos.

\section{Gráfico 1 - Percentual da população de 4 a 17 anos com deficiência que frequenta a escola}

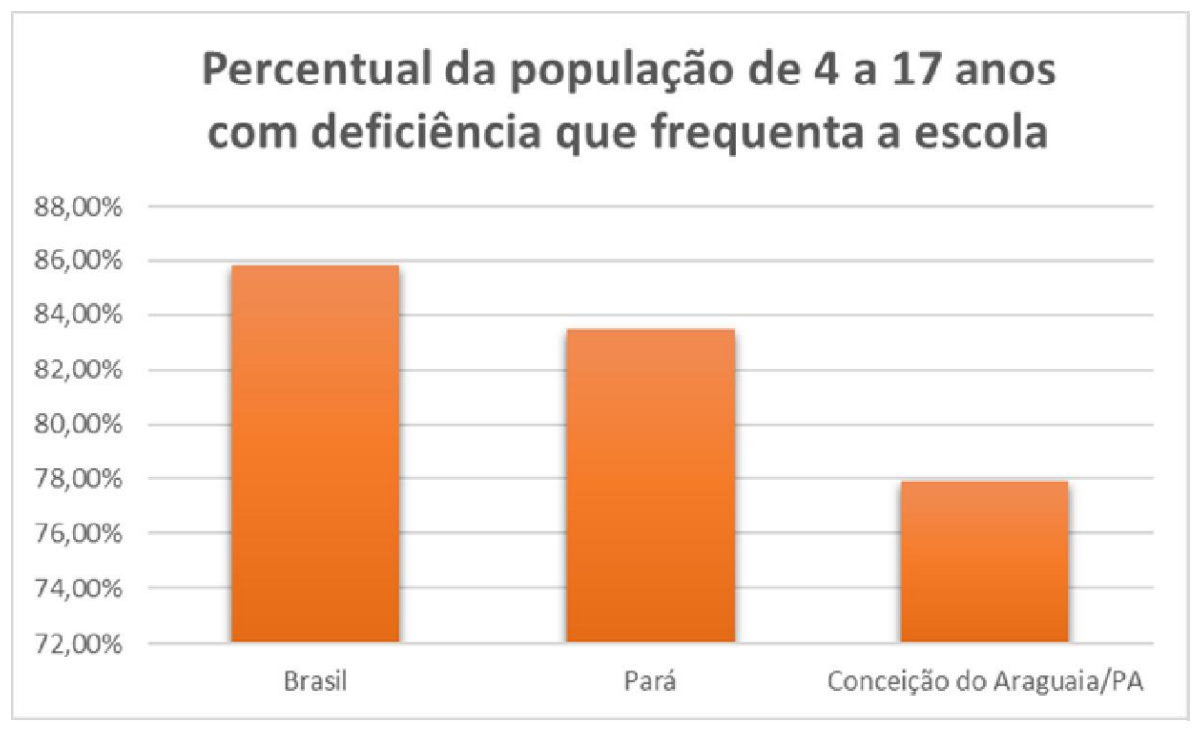

Fonte: IBGE/Censo Populacional -2010 
A Educação Especial do município de Conceição do Araguaia, se organiza seguindo as diretrizes da Politica Nacional de Educação Especial na Perspectiva da Educação Inclusiva (BRASIL, 2008), ofertando o ensino comum e o Atendimento Educacional Especializado.

Algumas escolas da zona urbana ofertam o Atendimento Educacional Especializado nas salas de recursos multifuncionais. Entretanto, até 2016, das 8 (oito) escolas localizadas na zona rural nenhuma dispunha de sala de recursos, mesmo possuindo alguns materiais para Atendimento Educacional Especializado (SEMED, 2016). O municipio de Conceição do Araguaia, tem 37 áreas de assentamentos de reforma agrária, com 8 escolas do campo vinculadas ao sistema público municipal de ensino. Quando analisamos o Censo da Educação Básica (2014-2016), no caso dos dados dos estudantes público-alvo da Educação Especial no município temos a seguinte realidade: cerca de $20 \%$ destes estão matriculados nas escolas do campo, sendo 50 alunos atendidos no ano de 2014, 42 no ano de 2015 e 71 no ano de 2016 .

Estudos realizados por Caiado e Meletti (2011), revelam que a relação entre a Educação Especial e a Educação do Campo ainda precisa/necessita ser aprofundada, considerando um silêncio histórico de produção científica nos grupos de pesquisas relacionados a essa temática. Segundo as autoras, trabalhar a interface entre essas duas grandes áreas é um desafio, levandose em conta que recentemente a Educação Especial e a Educação do Campo foram consideradas como um direito social.

Os dispositivos legais da relação entre a Educação Especial e a Educação do Campo se encontram em vários documentos, tais como:

- As Diretrizes Operacionais para a Educação Básica nas Escolas do Campo (BRASIL, 2002), estabelecem que:

Art.2 ${ }^{\circ}$ Estas Diretrizes, com base na legislação educacional, constituem um conjunto de principios e de procedimentos que visam a adequar o projeto institucional das escolas do campo às Diretrizes Curriculares Nacionais para a Educação de Jovens e Adultos, a Educação Especial, a Educação Indigena, a Educação Profissional de Nivel Técnico e a Formação de Professores em Nivel Médio na modalidade Normal. (BRASIL, 2002, p.2) 
- A Resolução $\mathrm{n}^{\circ}$ 2/2008b, que estabelece diretrizes complementares, normas e princípios para o desenvolvimento de Políticas públicas de atendimento da Educação Básica do Campo, reafirma:

$\S^{\circ}$ Os sistemas de ensino adotarão providências para que as crianças e os jovens portadores de necessidades especiais, objeto da modalidade de Educação Especial, residentes no campo, também tenham acesso à Educação Básica, preferentemente em escolas comuns da rede de ensino regular. (BRASIL, 2008, p.5)

- A Política Nacional de Educação Especial na Perspectiva da Educação Inclusiva (BRASIL, 2008a) afirma que:

A interface da Educação Especial na educação indígena, do campo e quilombola deve assegurar que os recursos, serviços e Atendimento Educacional Especializado estejam presentes nos projetos pedagógicos, construídos com base nas diferenças socioculturais desses grupos (BRASIL, 2008a, p.17)

- Documento da Conferência Nacional de Educação ${ }^{5}$ (BRASIL, 2010a), no eixo intitulado "Justiça Social, Educação e Trabalho: Inclusão, Diversidade e Igualdade", afirma que na construção de um sistema nacional articulado de educação são necessárias ações referentes às questões étnicoracial, indígena, do campo, das pessoas com deficiência, educação ambiental, crianças e adolescentes e jovens em situação de risco, educação de jovens e adultos e educação profissional. Quando se refere à Educação do Campo e a educação indígena há metas como:

m) Estimular a interface da Educação Especial na Educação do Campo, a fim de assegurar que os recursos, serviços e Atendimento Educacional Especializado estejam presentes nos projetos pedagógicos construídos com base nas diferenças socioculturais desse segmento. (BRASIL, 2010, p.137)

\footnotetext{
${ }^{5}$ Evento que discutiu Políticas para o Plano Nacional de Educação (PNE), que vigorará no período entre 2014 a 2024, que foi sancionado pela Presidente Dilma dia 25 de junho de 2014.
} 
Além dos dispositivos legais, a abordagem teórico-metodológico se dará mediante as contribuições dos pensadores da Teoria Crítica e seus comentadores. Dentro desse contexto, os resultados obtidos nesta pesquisa serão analisados e discutido tendo a Teoria Crítica como fundamentação da pesquisa. Ao escolher como fundamentação teórico-metodológico a Teoria Crítica, entendemos que ela se constitui o próprio método da pesquisa, por isso não vale delimitar aqui em pesquisa quantitativa ou qualitativa, porque, segundo a Teoria Crítica, estaria aprisionando o objeto de estudo.

A Teoria Crítica considera que a educação é capaz de combater a violência, a segregação, a discriminação e o preconceito quanto à sua manifestação na escola. A educação não é uma instrumentalização neutra, porque a escola possui uma natureza na sua prática cotidiana capaz de produzir moralmente e socialmente individuos, e para que ela possa funcionar de maneira ideal para além daquilo que ela teria como princípio.

A vida cotidiana é diversa, o que gera uma sociedade completamente distinta. Como se pode democratizar e se tonar uma sociedade mais inclusiva? Pensar a educação no seu sentido político como premência para o desenvolvimento de identidades críticas e reflexivas, no sentido de pensar a educação para contradição e resistências das injustiças sociais, é condição para uma sociedade justa, que propicia condições para o desenvolvimento e propagação de uma consciência verdadeira.

Adorno direciona a concepção de educação para escola quando afirma que a educação deve ser uma educação para a não dominação. Uma educação que tenha a capacidade de superar o conformismo e a indiferença, de trabalhar com o diferente, de arriscar; enfim, uma educação capaz de libertar de toda dominação e que oriente para a construção de um mundo mais correto, mais justo, o que para Adorno representava que o "objetivo de toda educação, é que Auschwitz não se repita" (1995, p.38).

\section{Metodologia}

Através da utilização do software SPSS (Statistics Syntax Editor), extraímos os dados estatísticos-educacionais que são divulgados pelo 
Instituto Nacional de Estudos e Pesquisas Educacionais Anísio Teixeira INEP. Os microdados do censo escolar nos ajudaram analisar indicadores oficiais da Educação Básica acerca das matrículas dos estudantes públicoalvo da Educação Especial que estudam nas regiões urbanas e rurais do município pesquisado neste estudo. Como também no universo das necessidades educacionais especiais, os dados levantados foram relativos às matrículas dos alunos público alvo da Educação Especial, a saber alunos com deficiência, transtornos globais do desenvolvimento, altas habilidades e superdotação das escolas localizadas nas áreas de distritos rurais de Conceição do Araguaia, no período de 2014 a 2016.

Seguidamente fizemos uma pesquisa de campo visitando as oito escolas do campo que atendem os alunos que residem nos trinta e sete projetos de assentamento da Reforma Agrária município lócus deste estudo. De posse do levantamento do quantitativo de matrículas de estudantes público-alvo da Educação Especial dos microdados do censo escolar, e do resultado das visitas às unidades escolares, foi escolhida a escola do campo que possui o maior número de matrículas nessa modalidade. Procedeu-se assim, o pedido de autorização a secretaria municipal de educação e a direção da escola selecionada com vistas ao desenvolvimento da pesquisa, que foi realizada segundo semestre de 2016 e primeiro semestre de 2017.

Neste estudo foram utilizados os procedimentos/instrumentos da coleta de dados: Observação na escola do lócus da pesquisa, com os devidos registros em diário de campo; análise documental do projeto políticopedagógico da escola e demais documentos relevantes encontrados in loco; entrevistas semiestruturadas com professores atuantes com os estudantes público-alvo da Educação Especial. O instrumento utilizado foi um questionário semiestruturado de caracterização que abordou a interface da educação especial na educação do campo, acompanhado do termo de consentimento livre e esclarecido.

Os sujeitos das entrevistas foram: um (1) membro da equipe gestora da escola lócus do estudo, um (1) professor atuante no Atendimento Educacional Especializado (AEE) e um (1) professor de cada área do 
conhecimento, a seguir: Códigos e Linguagens; Ciências Humanas e Sociais; Ciências Exatas e da Natureza; necessariamente atuantes em turmas em que estudantes público-alvo da Educação Especial estavam incluídos.

Alicerçados na Teoria Crítica como suporte teórico-metodológico do estudo, foram analisadas as observações realizadas na escola, as narrativas presentes nas entrevistas concedidas pelos profissionais da educação, os dados obtidos por intermédio do questionário de caracterização e os documentos da escola, procedeu-se a análise e interpretação dos dados da pesquisa, o que nos permitiram caracterizar como se dá essa relação entre a Educação Especial e a Educação do Campo no município pesquisado.

\section{Resultados e discussão}

O município de Conceição do Araguaia, perfilha na porção sul do Pará, o território tem sido desigualmente disputado nas suas diversas dimensões. De um lado, camponeses e populações tradicionais e, de outro, grandes projetos do agronegócio e da mineração. Desta forma, a educação nesta região consolida sua prática inserida num contexto de conflitualidades entre perspectivas e políticas de desenvolvimento e assume o papel de contribuir para a territorialização da produção e das políticas públicas que contribuam para a redução da pobreza e desigualdades.

Hoje, só em Conceição do Araguaia, existem 37 projetos de assentamento, com 4.270 famílias assentadas, numa área total de 227.193,62 ha, sendo que apenas um destes assentamentos foi desapropriado de uma área de cerca de 60.000 ha pertencente a um banco privado (INCRA, 2016). A seguir uma tabela que apresenta os projetos de assentamentos situados no município.

\section{Quadro 1 - Projetos de Assentamentos e familias assentadas no município de Conceição do Araguaia, PA - 2016}

\begin{tabular}{|l|l|l|l|}
\hline Ordem & Projeto de Assentamento & Área (HA) & Familias \\
\hline
\end{tabular}




\begin{tabular}{|c|c|c|c|}
\hline & (PA) & & $\begin{array}{c}\text { Assentadas e } \\
\text { Existentes }\end{array}$ \\
\hline 01 & Águas Claras & $1.434,11$ & 28 \\
\hline 02 & Apertar da Hora & $4.356,00$ & 69 \\
\hline 03 & Arraias & $4.006,00$ & 80 \\
\hline 04 & Canarana & $12.851,29$ & 303 \\
\hline 05 & Centro da Mata & $4.356,00$ & 90 \\
\hline 06 & Chibil & $2.488,00$ & 69 \\
\hline 07 & Cocalinho & $1.281,42$ & 31 \\
\hline 08 & Cristo Rei II & $1.390,00$ & 21 \\
\hline 09 & Consolação & $4.117,04$ & 86 \\
\hline 10 & Curral de Pedras & $8.223,23$ & 154 \\
\hline 11 & Estiva & $4.352,00$ & 60 \\
\hline 12 & Gaucha & $3.965,50$ & 89 \\
\hline 13 & Indiaporã & $2.639,00$ & 63 \\
\hline 14 & Inga & $10.650,42$ & 98 \\
\hline 15 & Inga II & $4.531,31$ & 65 \\
\hline 16 & Inga III & $3.368,15$ & 67 \\
\hline 17 & Joncon/ 3 Irmãos & $25.211,79$ & 374 \\
\hline 18 & Lontra & $2.441,18$ & 63 \\
\hline 19 & Maria Luiza & $3.649,63$ & 84 \\
\hline 20 & Marrecas do Araguaia & $3.676,34$ & 93 \\
\hline 21 & Menina Moça IV & $3.596,00$ & 64 \\
\hline 22 & Milhomem & $1.630,85$ & 53 \\
\hline 23 & Nazaré & $12.968,00$ & 243 \\
\hline 24 & Novo Araguaia & $3.747,00$ & 76 \\
\hline 25 & Paragominas & $1.554,75$ & 40 \\
\hline 26 & Padre Josimo Tavares & $60.655,70$ & 1.106 \\
\hline 27 & Pecosa/Chapéu de Palha & $7.922,72$ & 168 \\
\hline 28 & Pedra Preta & $2.447,68$ & 49 \\
\hline
\end{tabular}




\begin{tabular}{|l|c|c|c|}
\hline $\mathbf{2 9}$ & Primavera & $2.901,85$ & 42 \\
\hline $\mathbf{3 0}$ & Santa Cruz & $1.742,00$ & 42 \\
\hline $\mathbf{3 1}$ & Santa Mariana & $1.829,39$ & 42 \\
\hline $\mathbf{3 2}$ & Santa Eudóxia & $3.436,17$ & 80 \\
\hline $\mathbf{3 3}$ & Santo Antônio & $3.801,71$ & 77 \\
\hline $\mathbf{3 4}$ & São Domingos & $2.470,82$ & 62 \\
\hline $\mathbf{3 5}$ & São José dos 3 Morros & $2.500,00$ & 14 \\
\hline $\mathbf{3 6}$ & São Raimundo & 970,20 & 21 \\
\hline $\mathbf{3 7}$ & União Batente & $4.030,37$ & 104 \\
\hline & Total & $\mathbf{2 2 7 . 1 9 3 , 6 2}$ & $\mathbf{4 . 2 7 0}$ \\
\hline
\end{tabular}

Fonte: INCRA/Unidade Avançada de Conceição do Araguaia, PA, 2016

$\mathrm{Na}$ área de educação, a rede municipal de Conceição do Araguaia atendeu no ano de 2015, cerca de 5.679 estudantes matriculados em 14 (quatorze) escolas da zona urbana, e 08 (oito) na área rural. Cerca de 37,78\% do total de estudantes matriculados na rede municipal estão matriculados nas escolas do campo, ou seja são 2.146 discentes estudando na zona rural.

São 08 (oito) escolas do Campo vinculados ao sistema público municipal de ensino. Em 2015 foram cadastrados 42 estudantes públicoalvo da Educação Especial no município lócus de estudo.

Em 2016, foram inseridos no censo escolar 4.984 estudantes, destes, 2.200 estavam matriculados em áreas rurais, cerca de 44,14\% estavam inseridos nas escolas campesinas. Em relação ao público da Educação Especial que estudam no campo neste ano, foram cadastrados 71 estudantes. (MEC/INEP. Censo da Educação Básica: microdados, 2016).

Observa-se um aumento de mais de $70 \%$ de matrículas do público alvo da Educação Especial em escolas do campo quando comparados ao ano de 2015. Os dados do Censo Escolar de 2016, por meio do microdados, nos permitem cotejar a matrícula. Quanto à caracterização destes alunos, eles se distribuem na seguinte forma conforme o quadro 2 .

Observa-se que nos anos de 2015 e 2016 a maioria dos estudantes matriculados nas escolas do campo no município de Conceição do Araguaia, 
têm deficiência intelectual, deficiência física e visual. As escolas também enquadram nessa última categoria de deficiência os estudantes com baixa visão. A unidade escolar que possui o maior número de alunos público-alvo da Educação Especial nos dois anos cotejados da pesquisa é a Escola Municipal Vinte de Abril, localizada no Projeto de Assentamento (P.A) Padre Josimo Tavares.

Quadro 3 - Distribuição dos estudantes público-alvo da Educação Especial, por tipo de deficiência nas Escolas do Campo no municipio de Conceição do Araguaia,PA/ 2016.

\begin{tabular}{|c|c|c|c|c|c|}
\hline Escolas/Localidade & DV6 & $\mathbf{D A}^{7}$ & DF8 & DI ${ }^{9}$ & $\begin{array}{c}\text { Autis } \\
\text { mo }\end{array}$ \\
\hline $\begin{array}{lllll}\text { Esc. Mul. Antônio de } & \text { Freitas - } \\
\text { Alaçilândia } & & & \end{array}$ & 2 & 1 & 2 & 3 & 1 \\
\hline $\begin{array}{l}\text { Esc. Mul. Atiorô - PA Pecosa/Chapéu de } \\
\text { Palha }\end{array}$ & 1 & 0 & 0 & 2 & 0 \\
\hline $\begin{array}{l}\text { Esc. Mul. Centro da Mata - PA Centro da } \\
\text { Mata }\end{array}$ & 0 & 2 & 1 & 1 & 1 \\
\hline Esc. Mul. Francisco Alencar - PA Chibiu & 0 & 1 & 2 & 3 & 0 \\
\hline $\begin{array}{l}\text { Esc. Mul. Juscelino Kubitschek-Vila São } \\
\text { Jacinto }\end{array}$ & 1 & 0 & 0 & 0 & 1 \\
\hline $\begin{array}{l}\text { Esc. Mul. Curral de Pedra - PA Curral de } \\
\text { Pedra }\end{array}$ & 2 & 1 & 2 & 2 & 1 \\
\hline $\begin{array}{l}\text { Esc. Mul. Nova República }- \text { PA } \\
\text { Joncon/Lote } 8\end{array}$ & 1 & 2 & 4 & 6 & 2 \\
\hline $\begin{array}{l}\text { Esc. Mul. Vinte de Abril - PA Pe. Josimo } \\
\text { Tavares }\end{array}$ & 3 & 1 & 3 & 15 & 1 \\
\hline Total & 10 & 8 & 14 & 32 & 7 \\
\hline
\end{tabular}

Fonte: MEC/INEP. Censo da Educação Básica: microdados, 2016.

${ }^{6}$ Deficiência Visual

7 Deficiência Auditiva

8 Deficiência Física

${ }^{9}$ Deficiência Intelectual 
Nossas visitas à escola se iniciaram no segundo semestre de 2016. Em um primeiro momento, foi apresentada à proposta da pesquisa à equipe gestora da escola (direção/coordenação). Chegamos em um momento muito delicado do cenário educacional do município. Em virtude de que os professores municipais estavam há quatro meses com salários atrasados, as escolas da zona urbana já tinham deflagrado greve. Como a maioria dos professores que atuam na educação campesina do município de Conceição do Araguaia, possuem contratos temporários, muitos ficaram com medo de aderir ao movimento grevista.

Neste cenário de salários atrasados, iminência de uma greve, falta de merenda escolar, toda uma realidade de descaso com a educação pública, encontramos professores extremamente desestimulados e sem perspectivas. Ao fazermos a explanação da pesquisa e os critérios selecionados que levaram à escolha das escolas do campo, os objetivos elencados, alguns gestores ficaram bastante impressionados, pois segundo eles, nenhum pesquisador ou acadêmico tinha escolhido a escola do campo para ser tema de pesquisa, conforme sintetiza a fala de uma coordenadora:

"Eu fico admirada pela escolha das escolas do campo, pois todos os projetos de pesquisa, cursos, capacitação são voltados para as escolas da zona urbana. Nos sentimos isolados e até mesmo discriminados por estarmos longe da sede da cidade. É a primeira vez desde que estou nesta escola que alguém se propõe a pesquisar sobre a educação de estudantes com deficiência que estudam numa escola localizada no campo".

O forte sentimento de exclusão está presente na fala da coordenadora por todo um cenário de esquecimento e invisibilidade que as escolas campesinas vivem e nos convida a refletir sobre as contradições sociais existentes numa sociedade que exclui e oprime. A exclusão é reflexo de uma sociedade que tem no seu bojo a barbárie imposta ao longo do tempo. Para Adorno (1995, p.33) "a desbarbarização da humanidade é o pressuposto imediato da sobrevivência. Este deve ser o objetivo da escola, por mais restritos que sejam seu alcance e possibilidade”. A explicação da barbárie, em Adorno (1995, p.155), significa: 
A tese que gostaria de discutir é a de que desbarbarizar tornou-se a questão mais urgente da educação hoje em dia. O problema que se impõe nesta medida é saber se por meio da educação pode-se transformar algo de decisivo em relação à barbárie. Entendo por barbárie algo muito simples, ou seja, que, estando na civilização do mais alto desenvolvimento tecnológico, as pessoas se encontrem atrasadas de um modo peculiarmente disforme em relação a sua própria civilização. [...] Considero tão urgente impedir isto que eu reordenaria todos os outros objetivos educacionais por esta prioridade.

É preciso considerar que a Educação Inclusiva é ampla, pois perpassa por diversas modalidades de ensino, e tem como foco incluir grupos/comunidades (jovens e adultos, encarcerados, indígenas, pescadores, assentados, quilombolas, pessoas com deficiência, caiçaras, entre outros) historicamente excluídos da sociedade, como bem ratifica Mel Ainscow ( 2005, p.113):

[...] A inclusão abrange todas as crianças e jovens nas escolas; está focada na presença, na participação e na realização; inclusão e exclusão estão vinculadas, de maneira que a inclusão envolve o combate ativo à exclusão; a inclusão é vista como um processo sem fim.

A expressão inclusão é ampla no sentido de eliminar barreiras seja da pessoa com deficiência, seja de raça, de gênero e/ou barreiras sociais e educacionais. Nessa tarefa de buscar fragmentos que ponham em diálogo estas duas modalidades de educação, modalidades da problematização desse artigo, indagamos aos gestores sobre a escolarização dos estudantes com deficiência, transtornos globais do desenvolvimento e altas habilidades/superdotação que estudavam na escola. $\mathrm{Na}$ fala de outra gestora, ela considera que é um público que vem chegando nos últimos anos na escola e que esta tem um considerável número de alunos sem laudos de suas especificidades. Assim, os professores não sabem se trata de uma necessidade educacional especial como dislexia, discalculia, disortografia, hiperativismo, ou se trata de um aluno com deficiência intelectual ou sindrome como autismo. Ela pontua: 
"Até então nosso professor que está em sala de aula, ele não tem nenhum tipo de formação para lidar com alunos com deficiência, e muitas vezes esse aluno não tem laudo que aponta o seu tipo de necessidade. Existe alguma lei que alunos com deficiência não pode reprovar? Eu queria essa lei na minha mão para mostrar para alguns professores!"

Como bem retrata no discurso da gestora, há ainda muitos profissionais da educação leigos com respeito à Política Nacional na perspectiva Inclusiva (BRASIL, 2008), ou seja, a barbárie ainda resiste em muitos ambientes escolares onde estudantes com necessidades específicas têm suas demandas invisibilizadas. Para Damasceno (2010, p.38) é necessário desbarbarizar a escola, tornando-a democrática:

[...]é preciso 'desbarbarizar' a escola democratizando-a. Como pensar em espaço democrático onde o coletivo e a participação não se constituam? Pensar que os estudantes é que devem se adaptar à escola é barbarizá-la, é torná-la um espaço apenas para adaptação, é assumi-la como instância unicamente para a reprodução das contradições da sociedade burguesa de classes, é a materialização da 'pseudoformação'.

Seguidamente, perguntamos aos gestores das escolas do campo sobre o modelo de educação voltado para esses alunos, tendo em visto que a legislação prevê o atendimento para esse público na classe comum do ensino regular, e a oferta do Atendimento Educacional Especializado (AEE) no contraturno e de modo complementar e/ou suplementar nos espaços denominados salas de recursos multifuncionais (SRM). Um gestor/diretor relata:

\footnotetext{
"Não temos a sala de AEE, um ambiente para atendimento para alunos especiais. Os representantes do MEC estiveram aqui e nos cobraram através de relatório que se não tivermos a sala para atendimento desses alunos, a escola vai perder a autorização de funcionamento. Mas, no momento não temos condições de ter essa sala. Os alunos são informados no Censo escolar, o município recebe a verba para atendimento desses alunos, mas devido a condições dificeis que a prefeitura enfrenta, esse espaço não existe".
}

O relato evidencia algo que haviamos constatado em diálogo com a Coordenadora do Departamento da Educação Especial da Secretaria 
Municipal de Educação, isto é, que nenhuma das oito escolas do campo do município de Conceição do Araguaia, no ano de 2016, possuía a oferta do AEE. Algumas dessas escolas receberam materiais do MEC para estruturar as SRMs, entretanto não há a realização desse trabalho. Estudos realizados em duas cidades paraenses: Belém e Marabá, através do Observatório Nacional da Educação Especial realizadas em 2012 e 2013, também revelam que a população do campo dessas duas cidades está distante do AEE que continua urbanocêntrico, tanto em termos de atendimento quanto de modelo educacional.

Continuamos nossa entrevista, indagamos aos gestores, como também alguns professores, se conheciam a realidade dos estudantes público-alvo da Educação Especial e as demandas de aprendizagem que os mesmos apresentavam, assim como as atividades pedagógicas e de intervenção que a escola realizava no sentido de contribuir com o desenvolvimento desses alunos. Uma gestora/diretora narrou:

\footnotetext{
"Nós temos uma aluna chamada Renata, do $6^{\circ}$ ano, com baixa visão, a professora tem que fazer a tarefa diferenciada, com atividades ampliada. Inclusive tinhamos um aluno com sindrome de down e mudou-se para a cidade em virtude da falta de Atendimento Educacional Especializado. A gente se vira como pode, com recorte, com revistas, video aula. É dificil para gente trabalhar quando não temos capacitação e formação para lidar com esse público e estrutura para que a inclusão ocorra de fato".
}

Triste realidade verificada que evidencia o aumento do indice de evasão escolar na escola do campo, que se acentua nos alunos público alvo da Educação Especial, que enfrentam as barreiras atitudinais, arquitetônicas, de locomoção. Continuando nossa entrevista sobre a realidade enfrentada pelas escolas, perguntamos aos gestores se existiam algum profissional com formação para atuar na Educação Especial, ao que a coordenadora de uma escola do campo esclareceu:

"Nós temos um professor que atua no $5^{\circ}$ ano que se dedica a estudar essa área, ele compra o material para aprofundar nessa temática, pois não são todos que se identificam com essa modalidade. Solicitamos a Secretaria Municipal de Educação para ele atuar junto à sala de 
Atendimento Educacional Especializado, mas não permitiram, em virtude da dificuldade financeira que a prefeitura atravessa, eles estão somente aceitando lotação de professor regente em sala de aula".

Ao voltarmos em algumas escolas em março de 2017, para continuação da nossa pesquisa percebemos que algumas dimensões tinham avançado, consequência das eleições municipais no ano anterior, fruto da mudança da gestão municipal. Como visualização dessas transformações, a primeira delas é que nestas escolas foi preparada uma SRM com um professor para o AEE aos estudantes público-alvo da Educação Especial da escola. A relevância desse local como parte do sucesso da inclusão dos estudantes com necessidades específicas é caracterizada por Oliveira et. al. (2015, p. 112):

\footnotetext{
Nas SRM estão presentes saberes específicos, intrínsecos ao saber fazer do professor, exigindo dele domínio de aportes teórico-práticos e metodológicos específicos para atender aos alunos com necessidades especiais. Estes espaços são permeados de saberes fundamentais à prática do professor, e são saberes inerentes ao ato de ensinar, voltados para o respeito à autonomia e aos conhecimentos dos educandos a fim de estabelecer uma relação com os saberes curriculares e a convicção de que embora os avanços sejam lentos, a mudança é possivel
}

Nossas pesquisas apontaram que, no tocante aos estudantes públicoalvo da Educação Especial, a maioria apresentam distorção idade/série e em praticamente todas as escolas há alunos com deficiência. Cerca de 50\% desses estudantes não possuem laudo.

No sexto ano, é que se verifica a maior presença desse público, sendo que a maioria participa do AEE no mesmo horário de aula. Em nossas visitas nas escolas observamos que todos os estudantes que participam do AEE são atendidos de forma individual e/ou em duplas e participam no horário de suas aulas regulares, recebendo o atendimento de duas a três vezes por semana dependendo da necessidade especifica.

Em virtude de que muitos estudantes que participam das atividades no AEE moram distantes da sede da escola, e não há transporte escolar no 
contraturno para locomoção, fica inviabilizada/impossibilitada a participação do estudante dessa forma. Nesse cenário, o estudante fica privado da aula regular a que teria direito justamente para receber um atendimento especializado em virtude da sua necessidade específica.

A Diretriz Operacional para o AEE na Educação Básica (BRASIL,2009) recomenda o atendimento na SRM no contraturno. É bom frisar que a Escola Municipal Vinte de Abril começou esse atendimento no início de 2017, oito anos após a implementação da Política. A justificativa do aumento da distância que esses alunos residem e a dificuldade do transporte escolar rural acabam por acentuar a exclusão que o público-alvo da Educação Especial encontram no campo.

Nessa direção, os achados de Palma (2016) em três escolas do campo de um município paulista e de Nozu (2017) em três escolas de um município do Mato Grosso do Sul, relatam a ocorrência do atendimento no $\mathrm{AEE}$ simultaneamente ao turno de aula do aluno. Os estudantes da zona urbana de Conceição do Araguaia, recebem o atendimento no contraturno, por que os alunos do campo não podem receber os mesmos tratamentos? A exclusão está muito presente em mecanismos que se orientam pela inclusão, como Adorno (1995, p.157) especifica:

\begin{abstract}
Quando o problema da barbárie é colocado com toda sua urgência e agudeza na educação, e justamente em instituições como a sua, que desempenha um papel-chave na estrutura educacional da Alemanha hoje, então me inclinaria a pensar que o simples fato de a questão da barbárie estar no centro da consciência provocaria por si uma mudança. Por outro lado, que existam elementos de barbárie, momentos repressivos e opressivos no conceito de educação e, precisamente, também no conceito da educação pretensamente culta, isto eu sou o último a negar. Acredito que, e isso é Freud puro, justamente esses momentos repressivos da cultura produzem e reproduzem a barbárie nas pessoas submetidas a essa cultura.
\end{abstract}

Em uma das nossas visitas a uma escola do campo, acompanhamos o AEE na SRM de duas alunas, Bruna, de 10 anos, e Alice, de 06 anos, ambas em avaliação com suspeita de deficiência intelectual, cursando o segundo ano. As alunas foram retiradas do seu horário de aula regular para receber o atendimento especializado. Verificamos que a estudante Bruna conhece as 
letras, mas não consegue juntar as sílabas. A estudante Alice tem dificuldades na coordenação motora. A mãe teve um eclampse na gravidez, o que afetou o desenvolvimento cognitivo da aluna, a mesma tem crises epiléticas e toma remédio controlado, não conhece as letras e tem dificuldades de concentração.

Nesse acompanhamento, ouvimos um relato de uma mãe que desejava tirar seu filho com deficiência intelectual da escola, pois segundo ela o filho nunca aprenderia. Ela visualizava que o filho sofria muita discriminação por parte de outros alunos, por vezes vezes deixava ela triste/decepcionada com essa situação, conforme o seguinte depoimento:

\footnotetext{
"Estou pensando em retirar meu filho desta escola. Eu sinto que ele sofre muita discriminação na sala de aula pelos colegas, percebo que às vezes ele chega muito triste em casa pelos apelidos que os colegas colocam nele. Às vezes eu penso que ele nunca vai aprender".
}

Romper com esse modelo segregação, exclusão e de discriminação que impera nas nossas escolas é o desafio da Educação Inclusiva. Pensar em um modelo de educação para resistir à barbárie presente nos ambientes escolares é fundamental para que não tenhamos mais que ouvir/ler o relato triste dessa mãe. Adorno (1995) considera que desbarbarizar é a prioridade nesse momento da educação, visto que estamos num processo evolutivo, mas que ainda temos muitos indivíduos atrasados em seu pensamento. A exclusão está tão enraizada na organização da vida humana que é necessária e urgente a emancipação para romper com essa ideologia dominante, como bem enfatiza o pensamento de Adorno (1995, p. 35,36)

\footnotetext{
A própria falta de emancipação é convertida em ideologia [...] Mas, deparam-se, por outro lado, com as sólidas barreiras impostas pelas condições vigentes. Como não podem romper essas barreiras mediante o pensamento, acabam atribuindo a si mesmos, ou aos adultos, ou aos outros, esta impossibilidade real que lhes é imposta. Eles mesmos terminam por se dividir mais uma vez em sujeito e objeto. De qualquer modo, a ideologia dominante hoje em dia define que, quanto mais pessoas estiverem submetidas a contextos objetivos em relação aos quais são impotentes, ou acreditam ser impotentes, tanto mais ela se tornarão subjetiva esta impotência.
} 
Em todo instante precisamos lutar contra a pseudoinclusão, que mascarada de uma falsa ilusão de integração, quer perpetuar seu modelo de barbárie. A construção de uma sociedade mais humana, solidária/fraterna e acolhedora deve encontrar no ambiente escolar um local propício para a instauração do respeito e da aprendizagem das diferenças. Corroborando essa percepção, Costa e Damasceno (2012) registram que o movimento inclusivo na contemporaneidade tem como objetivo a democratização tanto do ensino quanto da sociedade. A importância de um espaço democrático é ratificado por Adorno (1995, p.142) ao afirmar que:

\begin{abstract}
Numa democracia, quem defende ideais contrários à emancipação, e, portanto, contrários à decisão consciente independente de cada pessoa em particular, é um antidemocrata, até mesmo se as idéias que correspondem a seus desígnios são difundidas no plano formal da democracia. As tendências de apresentação de ideais exteriores que não se originam a partir da própria consciência emancipada, ou melhor, que se legitimam frente a essa consciência, permanecem sendo coletivistasreacionárias. Elas apontam para uma esfera a que deveriamos nos opor não só exteriormente pela política, mas também em outros planos muito mais profundas.
\end{abstract}

Não basta somente acolher a pessoa com algum tipo de necessidade específica, mas é necessário efetivar as condições para a sua permanência e sucesso na escola. Não basta apenas usar utilizar a expressão que a escola é inclusiva, o ambiente escolar necessita ter condições de atendimento e os

professores precisam estar preparados para receber e atender os diversos tipos de demandas do processo de inclusão escolar.

\title{
Considerações finais
}

Nessa caminhada de tempos dificeis e perdas de direitos conquistados, precisamos desbarbarizar através de uma educação que nos emancipa e humaniza. Caracterizar essas duas modalidades da Educação Inclusiva em uma parte da região sul da Amazônia Paraense é voltar o olhar para essa educação com mais crítica, com responsabilidade sobre o processo histórico de transformação social. Alguém como sujeito histórico, que não deseja só 
passar pela vida, mas que deseja viver essa vida comprometida com a realidade social.

É relevante ressaltar que a Educação Especial no Brasil tem caráter pragmatista, comportamental, com viés americano, de treinamento, sem crítica social alguma, mas pelo contrário, é de adaptação ao meio. Cada vez mais precisamos nos posicionar e mostrar que há dentro da Educação Especial, muitas questões pelas quais nós temos que nos assumir politicamente, como bem ressalta Paulo Freire (1991, p.15) ao afirmar: “A educação é ato político".

Com este estudo foi possivel investigar e caracterizar como se organiza e se desenvolve a Educação Especial em uma escola do campo em um dos maiores projetos de assentamentos da reforma agrária do sul da Amazônia Paraense. Os resultados obtidos nesse estudo nos levam a considerar que a educação da pessoa com deficiência em assentamentos do município Conceição do Araguaia, ainda é bastante silenciada, aparecendo como tema tímido nas discussões dos gestores/diretores e, por conseguinte, na comunidade escolar. Os dados do censo escolar revelam um universo de estudantes com deficiência, transtornos globais do desenvolvimento e altas habilidades/superdotação estudando nas escolas do campo do município.

Nossos resultados apontam que a Educação Especial em assentamentos do município de Conceição do Araguaia, se realiza em condições precárias e, por conseguinte, há uma invisibilidade deste público, considerando que até o ano de 2016 nenhuma das escolas do campo oferecia o AEE para o público-alvo da Educação Especial. Considerando a Política de Educação Especial na perspectiva da Educação Inclusiva (BRASIL,2008), que prevê o atendimento para esse público na classe comum do ensino regular, e a oferta do $\mathrm{AEE}$, no contraturno e de modo complementar e suplementar nos espaços denominados salas de recursos multifuncionais (SRMs).

Algumas escolas municipais da zona urbana ofertam esse tipo de atendimento. A Educação Especial na zona rural não acontece, como se o privilégio dessa modalidade de ensino fosse somente para os moradores da 
cidade, resultando em um esquecimento cruel e irresponsável de descaso. Se as pesquisas em Educação Especial apontam os desafios nas escolas localizadas em áreas urbanas, estes se intensificam muito mais nas populações do campo.

Durante o período de pesquisa em nossas visitas a diversas comunidades rurais do município Conceição do Araguaia, pudemos verificar uma pauperização de muitas famílias. Um quadro assustador de realidade campesina conceicionense/araguaiana. Os desafios que a pessoa com deficiência encontra na zona urbana são imensos, o descaso e as mazelas são agravadas ainda mais nas populações do campo, principalmente pelo acirramento das contradições que a luta no campo traz.

Vivemos um período de desmontes das Politicas públicas de nucleação e fechamento de escolas do campo e, consequentemente, os espaços do AEE ficam comprometidos. Enfim, as barreiras que encontramos na Educação Especial das escolas da cidade, são agravadas nas escolas do campo, por todo o cenário de conflitos e descaso na história do campo brasileiro.

Ao nos assumir politicamente por uma educação contra a barbárie e por uma educação que nos emancipe e nos humanize, precisamos nos questionar: Qual tipo de Educação Especial queremos no campo e na cidade? Certamente uma Educação Especial no campo que considere as peculiaridades dos alunos com necessidades específicas que vivem e estudam no campo, com uma formação humana e emancipadora. Esse é o debate que precisamos aprofundar, considerando que este tipo de discussão ainda está em construção haja vista a ausência de pesquisas nessa interface na região Amazônica e, principalmente no sul e sudeste paraenses.

\section{Referências}

ADORNO, T. W. Educação e Emancipação. São Paulo: Paz e Terra, 1995.

Notas marginais sobre teoria e práxis. In: ADORNO, T. W. Palavras e sinais: modelo crítico. 2.ed. Petrópolis, RJ: Vozes, 1995. 
Dialética do esclarecimento: fragmentos filosóficos. Rio de Janeiro: Jorge Zahar, Ed., 1985.

AINSCOW, M. Developing inclusive education systems: what are the levers for change?. Journal of Educational Change, v. 6, n. 2, p. 109-124, 2005

ADORNO, T. W.; HORKHEIMER, M. Dialética do esclarecimento. Rio de Janeiro: Jorge Zahar, 1985

BRASIL. INCRA. Painel de assentamentos, 2016. Disponivel em: <http://painel.incra.gov.br/sistemas/index.php>.Acesso em: 26 de agosto 2016.

. Ministério da Educação. Instituto Nacional de Estudos e Pesquisas Educacionais Anísio Teixeira. Censo Escolar da Educação Básica $2015 . \quad$ Disponivel em: < http://www.inep.gov.br/basica/levantamentos/microdados.asp. > Acesso em: 30 jan. 2016

- Ministério da Educação. Instituto Nacional de Estudos e Pesquisas Educacionais Anísio Teixeira. Censo Escolar da Educação Básica 2016. Disponível em: < http://www.inep.gov.br/basica/levantamentos/microdados.asp. > Acesso em: 30 jan. 2017

IBGE. Censo demográfico, 2010. Disponível em: <http://www.ibge.gov.br/ home/estatistica/populacao/censo2000/ default.shtm>.Acesso em: 11 de jan 2016

. Ministério da Educação. Política Nacional de Educação Especial na Perspectiva da Educação Inclusiva. Brasília: MEC, 2008ª . Disponível em: <http://www.mec.gov.br>. Acesso em: 10 dez.2016

- Ministério da Educação. Secretaria de Educação Continuada, Alfabetização e Diversidade. Diretrizes Operacionais para a Educação Básica nas Escolas do Campo. Brasília: MEC/SECAD, 2002. Disponível em: $<$ http://www.mec.gov.br>. Acesso em: 12 jan.2016

. Ministério da Educação. Conselho Nacional de Educação. Câmara de Educação Básica. Resolução $n^{\circ} 2$, de 28 de abril de 2008b. Estabelece diretrizes complementares, normas e princípios para o desenvolvimento de políticas públicas de atendimento da Educação Básica do Campo. Disponível em: <http://www.mec.gov.br>. Acesso em: 12 jan.2016 
- Ministério da Educação. Documento Final da Conferência Nacional de Educação (CONAE 2010). Brasília:MEC,2010ª . Disponivel em: <http://www.mec.gov.br>. Acesso em: 12 jan.2016

- Resolução n. ${ }^{\circ} 4$, de 2 de Outubro de 2009. Institui as Diretrizes Operacionais para o Atendimento Educacional Especializado na Educação Básica, na modalidade da Educação Especial. Conselho Nacional de Educação. Câmara de Educação Básica. Brasília, DF, 2009.

CAIADO, K. R. M; MELETTI, S. M. F. Educação especial na educação do campo:20 anos de silêncio no GT 15. Revista Brasileira de Educação Especial, v.17, p.93-104,2011

COSTA \& DAMASCENO. Politicas Públicas de Educação e Inclusão: Sociedade, cultura e formação. In: Educação Profissional Inclusiva: desafios e perspectivas. Seropédica, RJ:EDUR, 2012.

DAMASCENO, Allan Rocha. Educação inclusiva e organização da Escola: Projeto pedagógico na perspectiva da teoria critica.Tese (Doutorado em Educação). Universidade Federal Fluminense. Niterói -Rio de Janeiro, 2010.

FERNANDES, B. M; CERIOLI, P. R; CALDART, R. S. Primeira Conferência Nacional -Por Uma Educação Básica do Campoll: texto preparatório. In: ARROYO, Miguel Gonzalez; CALDART, Roseli Salete; MOLINA, Mônica Castagna (Orgs.). Por uma educação do campo. 5. ed. Petrópolis: Vozes, 2011, p. 19-62.

FREIRE, P. Pedagogia do Oprimido, 50. ed. São Paulo: Paz e Terra, 1991.

HÉBETTE, J. A Velha questão da terra na Amazônia: a estrutura fundiária amazônica da colônia até hoje. Cruzando a Fronteira: 30 anos de estudo do campesinato na Amazônia. EDUFPA, Belém, 2004, Vol. I II e III.

IANNI, O. A luta pela terra: história social da terra e da luta pela terra numa área da Amazônia. Petrópolis, Vozes. 1979. 236p.

MARTINS, J de S. A militarização da questão agrária no Brasil. Petrópolis: Vozes, 1984.

. Expropriação e Violência: a questão política no campo. $3^{a}$ edição, São Paulo: Hucitec, 1991.

- O poder do atraso. Ensaios de sociologia da história lenta. 2a edição, São Paulo: Hucitec, 1999.

MAZZOTTA, Marcos J. S. Educação especial no Brasil: história e políticas públicas. 5. ed. São Paulo: Cortez, 2005. 
NOZU. W.C.S. Educação Especial e Educação do Campo: Entre porteiras marginais e fronteiras culturais. 2017. Tese (Doutorado em Educação Especial) - Universidade Federal da Grande Dourados, Dourados-MS,2017.

PALMA, D. T. Escolas do campo e atendimento educacional especializado em sala de recursos multifuncional. 2016. 140 f. Dissertação (Mestrado em Educação) - Universidade Estadual Paulista -Júlio de Mesquita Filholl, Araraquara, 2016.

OLIVEIRA, I. A; et. al. Atendimento Educacional em Salas de Recursos Multifuncionais de Escolas da Rede Municipal de Belém (PA). In: MENDES, E.M. et al. (Org.). Inclusão Escolar e os Desafios para a Formação de Professores em Educação Especial. São Carlos: Marquezine \& Manzini, 2015.p.111-136 